\title{
Chemo-photothermal Therapy Promoting Immunogenic Cell Death Based on NIR-II Light- responsive Drug Delivery Systems
}

\section{Lifeng Hang ( $\sim$ hanglf@ustc.edu.cn )}

Guangdong Second Provincial General Hospital https://orcid.org/0000-0003-3228-2375

\section{Wuming Li}

Guangdong Second Provincial General Hospital

\section{Dandan Men}

Jiangxi Science and Technology Normal University

\section{Hua Wen}

Guangdong Second Provincial General Hospital

\section{Xinfeng Tang}

USTC: University of Science and Technology of China

\section{Chunze Zhou}

USTC: University of Science and Technology of China

\section{Xiaofen Ma}

Guangdong Second Provincial General Hospital

\section{Guihua Jiang}

Guangdong Second Provincial General Hospital

\section{Research}

Keywords: Nanocarrier-based drug delivery systems, hollow copper sulfide nanoparticles, doxorubicin, chemo-photothermal therapy, immunogenic cell death

Posted Date: August 6th, 2021

DOl: https://doi.org/10.21203/rs.3.rs-770161/v1

License: (c) (i) This work is licensed under a Creative Commons Attribution 4.0 International License. Read Full License 


\section{Chemo-photothermal therapy promoting immunogenic cell death based on NIR-II light-responsive drug delivery systems}

Lifeng Hang ${ }^{1}{ }^{\#}$, Wuming $\mathrm{Li}^{1 \#}$, Dandan Men ${ }^{2 \#}$, Hua Wen ${ }^{1}$, Xinfeng Tang ${ }^{3}$, Chunze Zhou $^{4}$, Xiaofen $\mathrm{Ma}^{1}$, Guihua Jiang ${ }^{1}{ }^{1 *}$

${ }^{1}$ The Department of Medical Imaging, Guangdong Second Provincial General Hospital, Guangzhou, 518037, P. R. China

${ }^{2}$ Jiangxi Key Laboratory of Surface Engineering, Jiangxi Science and Technology Normal University, Nanchang, 330013, P. R. China

${ }^{3}$ Division of Molecular Medicine, Hefei National Laboratory for Physical Sciences at Microscale, the CAS Key Laboratory of Innate Immunity and Chronic Disease, School of Life Sciences, University of Science and Technology of China, Hefei, 230001, P. R. China

4 Interventional Radiology Department, The First Affiliated Hospital of USTC, Division of Life Sciences and Medicine, University of Science and Technology of China, Hefei 230001, P. R. China

${ }^{\#}$ These authors contributed equally to this work.

*Corresponding author:

Lifeng Hang, E-mail address: hanglf@ustc.edu.cn

Guihua Jiang, E-mail address: jianggh@gd2h.org.cn 


\section{Abstract}

Background: Several recent studies have well demonstrated that the chemotherapy or near-infrared-II (NIR-II) photothermal therapy (PTT) can induce immunogenic cell death (ICD). However, single treatment based on the independent chemotherapy or PTT to induce ICD may require high dose of drug, high laser power, or high temperature, which limits their clinical application. We hypothesize that combination of chemotherapy and NIR-II PTT possesses great promise to overcome respective limitations. This manuscript describes the development of polyethylene glycol (PEG) modified hollow $\mathrm{Cu}_{\mathrm{x}} \mathrm{S}$ nanoparticles (NPs) for synergistic chemo-photothermal therapy to effectively promote ICD.

Results: Hollow structure $\mathrm{Cu}_{\mathrm{x}} \mathrm{S}$-PEG NPs were prepared under mild condition by using $\mathrm{Cu}_{2} \mathrm{O}$ NPs as sacrificial templates. $\mathrm{Cu}_{\mathrm{x}} \mathrm{S}$ loaded with doxorubicin (Dox) as NDDSs were characterized for hydrate particle size and surface charge. The morphology, photothermal effect, drug loading/releasing abilities, synergistic chemo-photothermal therapy, and ICD from synergistic therapy of $\mathrm{Cu}_{\mathrm{x}} \mathrm{S}-\mathrm{PEG}$ NPs have been investigated. The in vitro outcomes of ICD and chemo-photothermal therapy were assessed in EMT-6 cells. In vivo therapeutic studies and immunoreaction were performed in EMT-6 bearing mice where therapeutic outcomes were assessed by tumor volume, immunohistochemical staining, and expression of $\mathrm{CD}^{+}$cytotoxic T-lymphocytes. The $\mathrm{Cu}_{\mathrm{x}} \mathrm{S}$-PEG NPs with hollow structure show high drug loading capacity ( $255 \mu \mathrm{g}$ Dox per $\mathrm{mg}$ of $\mathrm{Cu}_{\mathrm{x}} \mathrm{S}$ NPs) and stimuli-responsive drug release triggered by NIR-II laser irradiation. The chemo-photothermal strategy more 
effectively induces ICD than that of the single treatment, accompanying with the release of adenosine triphosphate, pre-apoptotic calreticulin, and high mobility group box-1. Finally, the synergistic chemo-photothermal therapy based on the Dox $/ \mathrm{Cu}_{\mathrm{x}} \mathrm{S}$-PEG NPs promotes $\mathrm{CD}^{+}$cytotoxic T-lymphocytes infiltration into tumors and achieves $\sim 98.5 \%$ tumor elimination.

Conclusion: Therefore, our study emphasizes that the great potentials of $\mathrm{Cu}_{\mathrm{x}} \mathrm{S}-\mathrm{PEG}$ NPs can be used as NIR-II light-responsive NDDSs for the applications of biomedicine and immunotherapy.

Keywords: Nanocarrier-based drug delivery systems, hollow copper sulfide nanoparticles, doxorubicin, chemo-photothermal therapy, immunogenic cell death 


\section{Background}

Recently, several studies have well demonstrated that the chemotherapy or photothermal therapy (PTT) in the second near-infrared (NIR-II) window can induce immunogenic cell death (ICD), accompanying with the release of damage-related molecular patterns (DAMPs), which serve as immunostimulatory "danger" signals to elicit $\mathrm{T}$ cell activation [1-5]. However, single treatment based on the independent chemotherapy or PTT to induce ICD may require high dose of drug, high laser power, or high temperature, which limits their clinical application $[6,7]$. We hypothesize that combination of chemotherapy and NIR-II PTT possesses great promise to overcome respective limitations (i.e. requirement of high laser power, high dose of drug, and less efficient therapeutic efficacy, etc.) and more effectively induces ICD to minimize damage to healthy tissues. Therefore, rationally designing drug delivery systems for chemo-photothermal therapy and improving ICD efficiency is the key to this study.

Compared to the traditional chemotherapy, nanocarrier-based drug delivery systems (NDDSs) have great prospects for precise cancer therapy due to its higher bioavailability, multifunctionality, and low side effects for non-target tissues [8-13]. In particular, NIR-II light-responsive NDDSs serve as promising modalities to realize the demand of drug release at the target disease site and combination with other therapeutic modes [14-18]. Light has been widely used as an external stimulus to control drug release because of its unique advantages such as safety, minimal cross-reaction, and spatiotemporal precision $[19,20]$. In addition, the NIR-II light could penetrate a few inches into tissues deeper than NIR-I or visible light, and 
displayed no apparent damage to tissues or cells [21, 22]. Meanwhile, based on the photothermal conversion agents (PTCAs) as NDDSs, NIR-II light can be converted into heat for PTT, thereafter triggering drug release from the nanocarriers through thermal effect. Moreover, PTT is a complementary approach to enhance chemotherapeutic efficiency. Thus, using PTCAs as NIR-II light-responsive NDDSs can effectively combine chemotherapy and PTT, which has potential to promote tumor ICD.

Various PTCAs such as noble metal, carbon materials, metal oxide and metal sulfide NPs have been developed to generate heat efficiently for NIR light-responsive NDDSs [23-29]. For example, noble metal nanoparticles (NPs) (gold nanorods, gold nanoparticle agglomerates, platinum NPs) and drugs have been encapsulated into polymeric micelles to create vectors which allow NIR light-triggered drug release [30-35]. Carbon materials are also able to absorb NIR light and generate heat, and therefore the high temperature controls drug delivery from vectors containing carbon materials [36]. In addition, nanocarriers containing metal sulfide or metal oxide as PTCAs release cargoes through photothermal conversion under NIR laser irradiation $[37,38]$. However, the reported NIR light-responsive vectors encapsulating both PTCAs and drugs have some limitations including high cost, relatively low drug loading capacity, premature drug leakage, and complex preparation process, which prevented their further widespread applications. Therefore, development of NIR-II light-responsive NDDSs with high drug loading capacity, low cost, and facile preparation process is demanded. 
Among the various NIR-II PTCAs, copper sulfide has an optical absorption band peaking wavelength at NIR-II region caused by the $d-d$ energy band transition of $\mathrm{Cu}^{2+}$ ions which is independent of the dielectric constant of the surrounding medium [39]. Further, copper sulfide is much less expensive than other NIR-II PTCAs. Different from embedding PTCAs in nanocarriers, hollow nanostructured copper sulfide which exhibits numerous mesoporous pores and a large specific surface area has great application potential to be used as NIR-II light-responsive NDDSs [40]. Importantly, hollow copper sulfide can be eliminated from the living body by slow dissociation of $\mathrm{Cu}$ ion from NPs, indicating low biotoxicity of copper sulfide in vivo [41].

In this work, we develop a NIR-II photo-responsive NDDS mediated hollow nanostructured copper sulfide $\left(\mathrm{Cu}_{\mathrm{x}} \mathrm{S}\right)$ with modification of polyethylene glycol-lipoic acid (PEG-LA) for drug delivery, NIR-II PTT, and effectively promoting tumor ICD. As illustrated in Figure 1A, the hollow $\mathrm{Cu}_{\mathrm{x}} \mathrm{S}$ NPs are first prepared through $\mathrm{Cu}_{2} \mathrm{O}$ NPs template under mild condition. Then, drug molecules (doxorubicin) are loaded into hollow $\mathrm{Cu}_{\mathrm{x}} \mathrm{S}$ NPs (Defined as Dox/Cu $/ \mathrm{Cu}_{\mathrm{x}} \mathrm{S}$ NPs), resulting in a drug a loading factor as high as $\sim 255 \mu \mathrm{g}$ Dox per mg of $\mathrm{Cu}_{\mathrm{x}} \mathrm{S}$ NPs, and the obtained Dox $/ \mathrm{Cu}_{\mathrm{x}} \mathrm{S}$ NPs are subsequently modified with PEG-LA as Dox $/ \mathrm{Cu}_{\mathrm{x}} \mathrm{S}$-PEG NPs. The Dox $/ \mathrm{Cu}_{\mathrm{x}} \mathrm{S}-\mathrm{PEG}$ NPs exhibit a controllable drug release manner triggered by the NIR-II laser irradiation (Figure 1B). Moreover, excellent photothermal effect of Dox/Cu $\mathrm{u}_{\mathrm{x}} \mathrm{S}-\mathrm{PEG}$ NPs has been demonstrated benefiting from strong NIR-II absorption. By synergistic chemo-photothermal therapy, the Dox/Cu $\mathrm{S}$-PEG NPs can effectively induce ICD, 
accompanying with the release of DAMPs from dying cancer cells. In addition, we found that DAMPs such as adenosine triphosphate (ATP), pre-apoptotic calreticulin (CRT), and high mobility group box-1 (HMGB-1) in dying cells induced by the chemo-photothermal therapy could simultaneously trigger immune responses (Figure 1C). Both in vitro and in vivo results well demonstrated that such multifunctional nanoplatforms could achieve excellent efficiency for tumor suppression. This work develops a NIR-II light-responsive NDDS based on a single-component hollow $\mathrm{Cu}_{\mathrm{x}} \mathrm{S}$ NPs for synergistic chemo-photothermal therapy and effectively inducing ICD.

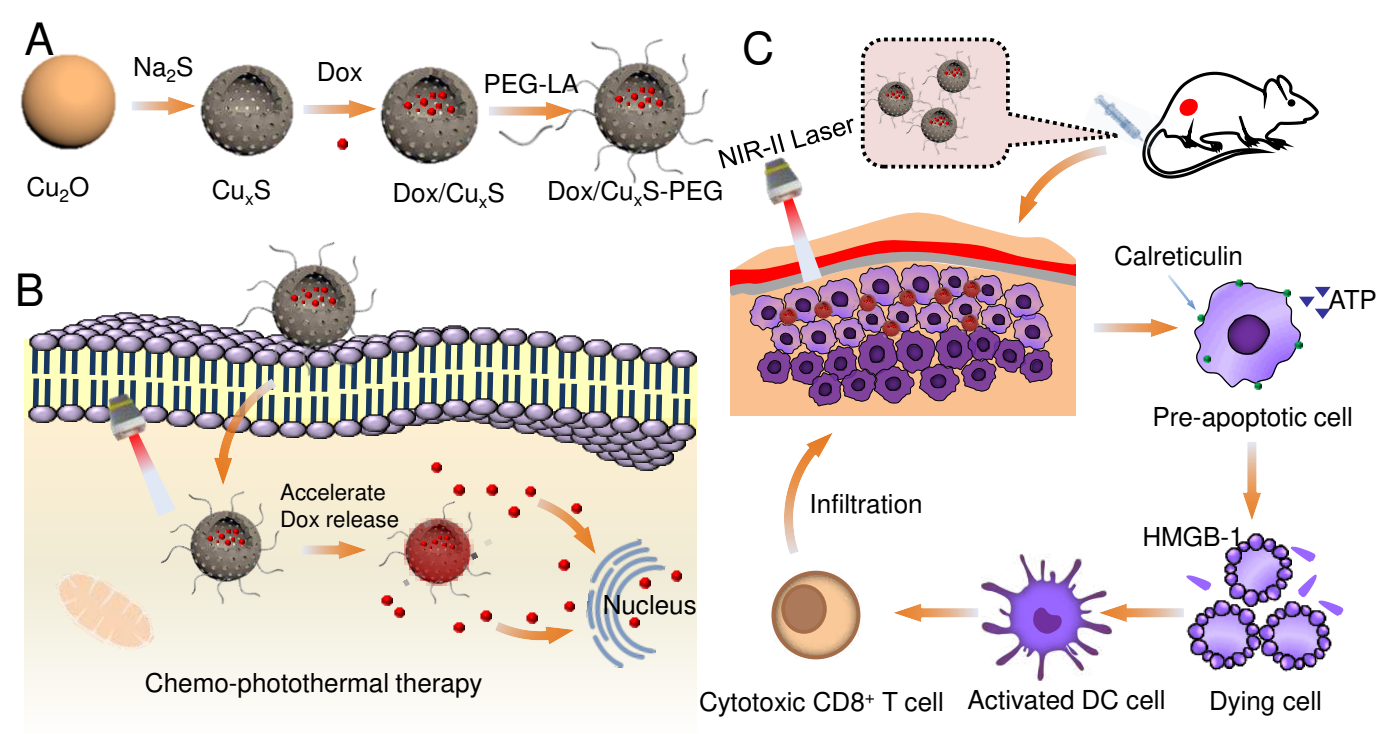

Figure 1. Schematic diagram of the preparation and bio-applications of hollow Cu $\mathbf{u}_{\mathrm{x}}$ S-PEG NPs. (A) The synthesis process of Dox/Cu $\mathrm{u}_{\mathrm{x}} \mathrm{S}-\mathrm{PEG}$ NPs. (B) The Dox $/ \mathrm{Cu}_{\mathrm{x}} \mathrm{S}$-PEG NPs for synergistic chemo-photothermal therapy. (C) The chemo-photothermal therapy induces ICD accompanying with releasing tumor-associated immunogenic factors which are presented to T cells. 


\section{Results and discussion}

\section{Preparation and characterizations of Dox/Cu $\mathrm{Cu}_{\mathrm{x}} \mathrm{S}$-PEG NPs}
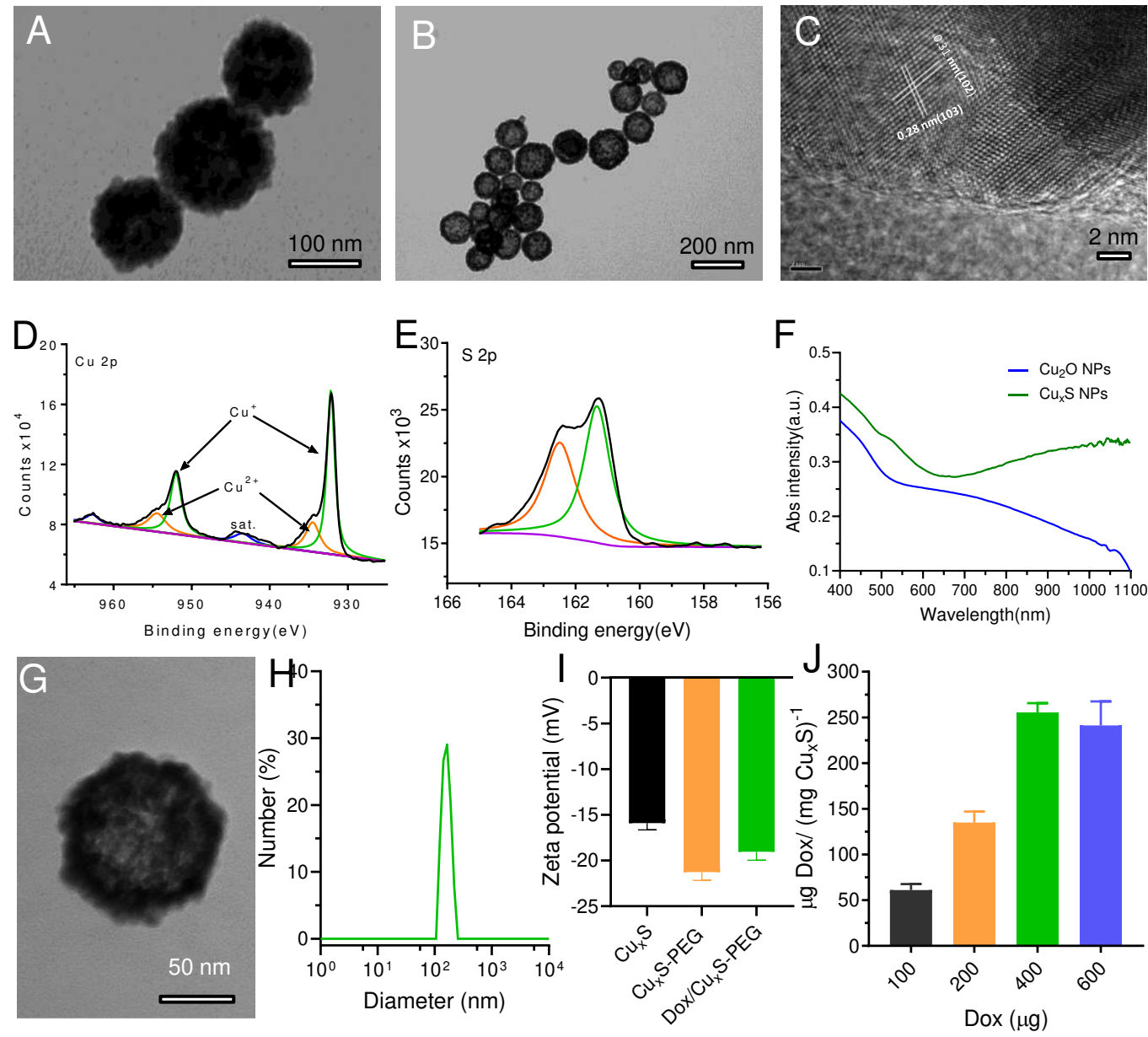

Figure 2. Characterizations of Dox/Cu $\mathbf{u}_{\mathrm{x}} \mathrm{S}$-PEG NPs. Representative transmission electron microscopy (TEM) images of (A) $\mathrm{Cu}_{2} \mathrm{O}$ nanospheres and (B) hollow $\mathrm{Cu}_{\mathrm{x}} \mathrm{S}$ NPs. (C) HRTEM image of hollow $\mathrm{Cu}_{\mathrm{x}} \mathrm{S}$ NPs. XPS spectra of (D) $\mathrm{Cu} 2 \mathrm{p}$ and (E) S $2 \mathrm{p}$ from $\mathrm{Cu}_{\mathrm{x}} \mathrm{S}$ NPs. (F) UV-Vis-NIR absorption spectra of the $\mathrm{Cu}_{2} \mathrm{O}$ nanospheres and hollow $\mathrm{Cu}_{\mathrm{x}} \mathrm{S}$ NPs. (G) The TEM image of hollow $\mathrm{Cu}_{\mathrm{x}} \mathrm{S}$-PEG NPs. (H) Hydrate particle size of $\mathrm{Cu}_{\mathrm{x}} \mathrm{S}$-PEG NPs. (I) The Zeta potentials of $\mathrm{Cu}_{\mathrm{x}} \mathrm{S}, \mathrm{Cu}_{\mathrm{x}} \mathrm{S}$-PEG, and Dox/Cu $u_{\mathrm{x}} \mathrm{S}$-PEG NPs. (J) The Dox loading capacity of per mg of hollow $\mathrm{Cu}_{\mathrm{x}} \mathrm{S}$-PEG under different mass of feeding Dox.

Utilizing $\mathrm{Cu}_{2} \mathrm{O}$ nanospheres as $\mathrm{Cu}_{\mathrm{x}} \mathrm{S}$ NPs precursor and template, we report a mild formation of hollow $\mathrm{Cu}_{\mathrm{x}} \mathrm{S}$ NPs through a facile reduction method in aqueous solution.

The precursor $\mathrm{Cu}_{2} \mathrm{O}$ nanospheres are synthesized through one-step method, in which PVP is used as the stabilizing agent, copper nitrate as the $\mathrm{Cu}_{\mathrm{x}} \mathrm{S}$ NPs precursor, and 
ethylene glycol (EG) and deionized water as the reaction solvent. Typical transmission electron microscopy (TEM) images (Figure 2A) reveal that the $\mathrm{Cu}_{2} \mathrm{O}$ nanospheres are spherical NPs with narrow size distribution (Figure S1) and average size about $\sim 123$ nm. To obtain hollow $\mathrm{Cu}_{\mathrm{x}} \mathrm{S}$ NPs, the $\mathrm{Cu}_{2} \mathrm{O}$ nanospheres as the sacrificial templates react with $\mathrm{Na}_{2} \mathrm{~S}$ solution dropwise under vigorous stirring. Upon the addition, $\mathrm{Na}_{2} \mathrm{~S}$ continuously etched $\mathrm{Cu}_{2} \mathrm{O}$ to fabricate hollow nanostructure immediately meanwhile the porous channels in the resultant NPs, which has the potential for loading drugs. Representative TEM and scanning electron microscopy (SEM) images (Figure 2B and Figure S2) reveal spherical hollow nanostructure with narrow size distribution (Figure S3) and average diameter about $\sim 125 \mathrm{~nm}$. To further characterize the hollow $\mathrm{Cu}_{\mathrm{x}} \mathrm{S}$ NPs, the high-resolution transmission electron microscopy (HRTEM) image (Figure 2C) shows that the lattice fringes corresponding to the (103) and (102) plane of $\mathrm{Cu}_{\mathrm{x}} \mathrm{S}$ crystal, indicating that the obtained hollow NPs is $\mathrm{Cu}_{\mathrm{x}} \mathrm{S}$. In addition, the powder X-ray diffraction (PXRD) patterns (Figure S4) of hollow NPs verifies that the all diffraction peaks are assigned to the $\mathrm{Cu}_{\mathrm{x}} \mathrm{S}$ crystal (PDF\#41-0959) [42]. Next, the high-resolution X-ray photoelectron spectroscopy (XPS) spectrum of $\mathrm{Cu} 2 \mathrm{p}$ exhibit $\mathrm{Cu}$ element in NPs possessed $\mathrm{Cu}^{+}$and $\mathrm{Cu}^{2+}$ (Figure 2D), and $\mathrm{S}$ element is $\mathrm{S}^{2-}$ state (Figure 2E) [43]. Furthermore, the corresponding UV-vis-NIR spectrum (Figure 2F) of hollow $\mathrm{Cu}_{\mathrm{x}} \mathrm{S}$ NPs showed the optical absorption band peaking wavelength at NIR region (range from NIR-I to NIR-II), which displayed the potential for the NIR-II phototherapy. These results well demonstrated that we successfully achieved hollow $\mathrm{Cu}_{\mathrm{x}} \mathrm{S}$ NPs with absorption at NIR-II region. 
To improve the biocompatibility of Dox/ $\mathrm{Cu}_{\mathrm{x}} \mathrm{S}$ NPs, PEG-LA due to good biocompatibility and long-term circulation is used to modify the hollow NPs based on the $\mathrm{Cu}-\mathrm{S}$ bond. The typical TEM image (Figure 2G) displays the observed faint dense corona surrounding the surface of $\mathrm{Cu}_{\mathrm{x}} \mathrm{S}$ NPs, demonstrating that a uniform PEG layer is coated on the hollow $\mathrm{Cu}_{\mathrm{x}} \mathrm{S}$ NPs $\left(\mathrm{Cu}_{\mathrm{x}} \mathrm{S}-\mathrm{PEG}\right)$. The average hydrodynamic size of $\mathrm{Cu}_{\mathrm{x}} \mathrm{S}$-PEG NP is $\sim 120 \mathrm{~nm}$ (Figure 2H), consistent with that of the $\mathrm{Cu}_{2} \mathrm{O}$ templates. Therefore, the hollow $\mathrm{Cu}_{\mathrm{x}} \mathrm{S}$ NPs have great potential to loading with antitumor drugs for chemotherapy, and we select Dox molecules as a model drug to evaluate their capacity. Meanwhile, the Zeta potential of $\mathrm{Cu}_{\mathrm{x}} \mathrm{S}-\mathrm{PEG}$ NPs with strong negative charge $(-21.2 \mathrm{mV})$ is higher than than that of the pristine $\mathrm{Cu}_{\mathrm{x}} \mathrm{S}$ NPs $(-15.9 \mathrm{mV})$ (Figure 2I). After loaded with positively charged Dox, the Zeta potential of Dox/Cu $\mathrm{Cu}_{\mathrm{x}} \mathrm{S}$-PEG NPs decreases to $-19.3 \mathrm{mV}$, indicating the successful Dox loading in NPs. Then, the loading capacity of Dox was measured by UV-vis spectra according to the standard line relation between concentration and absorption intensity (Figure S5). The UV-vis spectra of feeding Dox in solution and supernatant were respectively recorded (Figure S6), and the maximum loading capacity of Dox in hollow $\mathrm{Cu}_{\mathrm{x}} \mathrm{S}$ NPs is quantified to be $\sim 255 \mu$ g Dox per mg of NPs (Figure 2J).

Properties of $\mathrm{Cu}_{\mathrm{x}} \mathrm{S}$-PEG NPs for drug releasing and in vitro chemo-photothermal therapy 



$\mathrm{Cu}_{\mathrm{x}} \mathrm{S}-\mathrm{PEG}$

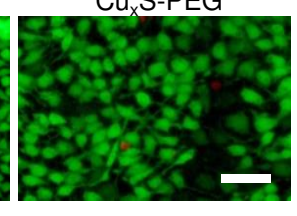

Dox

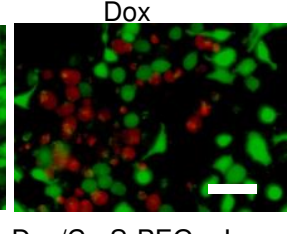

$\mathrm{Cu}_{\mathrm{x}} \mathrm{S}-\mathrm{PEG}+\mathrm{Laser}$

Dox $/ \mathrm{Cu}_{\mathrm{x}} \mathrm{S}-\mathrm{PEG}+$ Lase
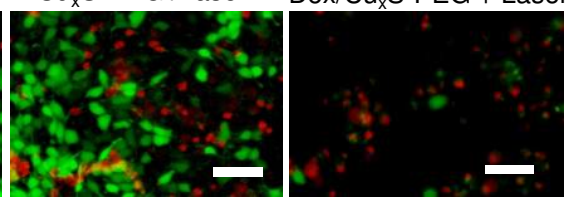

Figure 3. Drug releasing and in vitro chemo-photothermal therapy of Dox/Cu $\mathrm{Cu}_{\mathrm{x}} \mathrm{S}$-PEG NPs. (A) The UV-vis-NIR spectra of $\mathrm{Cu}_{\mathrm{x}} \mathrm{S}$-PEG NPs, Dox $/ \mathrm{Cu}_{\mathrm{x}} \mathrm{S}$-PEG NPs, and Dox. (B) The photothermal conversion curves of $\mathrm{Cu}_{\mathrm{x}} \mathrm{S}$-PEG NPs dispersions with different concentrations $\left(0,50,100\right.$, and $\left.200 \mu \mathrm{g} \cdot \mathrm{mL}^{-1}\right)$. The dispersions are irradiated with a $1064 \mathrm{~nm}$ laser $\left(1.0 \mathrm{~W} \cdot \mathrm{cm}^{-2}\right)$. (C) Dox release performance at $\mathrm{pH}=6.0$ and 7.4 with or without laser irradiation $\left(1.0 \mathrm{~W} \cdot \mathrm{cm}^{-2}\right)$. (D) Fluorescence images of EMT-6 cells after treated with Dox $/ \mathrm{Cu}_{\mathrm{x}} \mathrm{S}-\mathrm{PEG} \mathrm{NPs}$ and Dox/Cu $\mathrm{Cu}_{\mathrm{x}} \mathrm{S}$-PEG NPs plus NIR-II laser, respectively. The red and blue signals represent the Dox fluorescence and DAPI-stained cell nuclei, respectively. (E) MIF of Dox in the cell at different time point. (F) Cell viability of EMT-6 cells after treated with free Dox, Dox/Cu $/ u_{x}$ S-PEG NPs and Dox/Cu $\mathrm{Cu}_{\mathrm{x}} \mathrm{S}$-PEG NPs plus NIR-II laser. (G) Propidium iodide (PI) and Calcein-AM staining of the EMT-6 cells after administration with different groups: PBS, $\mathrm{Cu}_{\mathrm{x}} \mathrm{S}$-PEG NPs, Dox, Dox $/ \mathrm{Cu}_{\mathrm{x}} \mathrm{S}$-PEG NPs, $\mathrm{Cu}_{\mathrm{x}} \mathrm{S}$-PEG NPs plus laser, and Dox/Cu $\mathrm{Cu}_{\mathrm{x}} \mathrm{S}$-PEG NPs plus laser, was measured by fluorescence microscope. 
Compared with the absorption spectrum of the hollow $\mathrm{Cu}_{\mathrm{x}} \mathrm{S}$-PEG NPs, absorption spectrum of Dox/CuxS-PEG NPs shows a wide peak in the range of 380 600 nm, which is derived from the encapsulated Dox molecules (Figure 3A), further indicaiting the successful Dox loading in NPs. Next, the photothermal conversion performance of hollow $\mathrm{Cu}_{\mathrm{x}} \mathrm{S}$-PEG NPs was studied by irradiating the $\mathrm{Cu}_{\mathrm{x}} \mathrm{S}$-PEG NPs aqueous dispersions with $1064 \mathrm{~nm}$ laser $\left(1.0 \mathrm{~W} \cdot \mathrm{cm}^{-2}\right)$ under different concentration $\left(0,50,100\right.$, and $\left.200 \mu \mathrm{g} \cdot \mathrm{mL}^{-1}\right)$. The recorded temperature change curves of hollow $\mathrm{Cu}_{\mathrm{x}} \mathrm{S}$-PEG NPs in PBS solution rapidly increases within $4 \mathrm{~min}$, and then reached to a plateau. When the NPs concentrations increases from 50 to $200 \mu \mathrm{g} \cdot \mathrm{mL}^{-1}$, the temperature change $(\Delta \mathrm{T})$ is $16.6,24.1$, and $27.9{ }^{\circ} \mathrm{C}$ (Figure 3B), respectively. In stark contrast, the temperature of PBS solution shows negligible temperature increase $\left(\sim 2.3{ }^{\circ} \mathrm{C}\right)$ under same conditions. Then, the photothermal stability of $\mathrm{Cu}_{\mathrm{x}} \mathrm{S}$-PEG NPs $\left(50 \mu \mathrm{g} \cdot \mathrm{mL}^{-1}\right)$ is investigated by repeatedly irradiating aqueous dispersions for four ON/OFF cycles. No significant reduction was observed over the four cycles (Figure S7), suggesting that the $\mathrm{Cu}_{\mathrm{x}} \mathrm{S}$ NPs are photothermal stability for the NIR-II PTT. Therefore, the hollow $\mathrm{Cu}_{\mathrm{x}} \mathrm{S}$ NPs can be used for NIR-II PTT for triggering drug releasing.

The Dox releasing behavior was studied in PBS solutions (Dox $/ \mathrm{Cu}_{\mathrm{x}} \mathrm{S}$ NPs: 100 $\left.\mu \mathrm{g} \cdot \mathrm{mL}^{-1}\right)$ at different $\mathrm{pH}(6.0$ and 7.4$)$ with or without laser irradiation $\left(1.0 \mathrm{~W} \cdot \mathrm{cm}^{-2}\right)$ for 3 min. Under the slightly acidic condition $(\mathrm{pH}=6.0)$, Dox release rate is faintly faster than that of under neutral conditions $(\mathrm{pH}=7.4)$. At $\mathrm{pH} 6.0$ after $24 \mathrm{~h}$, the released Dox amount reached to $22 \%$ which is higher than that at $\mathrm{pH}=7.4(\sim 13.1 \%)$ 
(Figure 3C), deriving from the increased hydrophilia and protonation of Dox under acid environment. In addition, a explosive release of Dox observed under laser irradiation due to the rapid local temperature increase which can accelerate Dox dissolution from the NPs. Moreover, accumulated Dox amount in acidic and neutral environment under laser irradiation after $12 \mathrm{~h}$ is respectively almost 3.5 -fold $(51.7 \%$ vs $14.6 \%)$ and 4.1 -fold (35.1\% vs $8.4 \%)$ as that without irradiation. Therefore, hollow $\mathrm{Cu}_{\mathrm{x}} \mathrm{S}$ NPs can be used as NIR-II light-responsive NDDSs for on-demand drug delivery.

Before evaluating the behavior of intracellular drug delivery, the endocytosis and cytotoxicity of hollow $\mathrm{Cu}_{\mathrm{x}} \mathrm{S}$-PEG NPs have been measured by the inductively coupled plasma mass spectrometry (ICP-MS) and MTT assay, respectively. Firstly, $\mathrm{Cu}_{\mathrm{x}} \mathrm{S}-\mathrm{PEG}$ NPs (50 and $\left.100 \mu \mathrm{g} \cdot \mathrm{mL}^{-1}\right)$ are incubated with EMT-6 cells for different time $(1,2,4$, and $6 \mathrm{~h}$ ), and the concentration and incubation time-dependent phenomena are observed (Figure S8). Next, the cytotoxicity of $\mathrm{Cu}_{\mathrm{x}} \mathrm{S}$-PEG NPs was measured with various concentrations (ranging from $0 \sim 100 \mu \mathrm{g} \cdot \mathrm{mL}^{-1}$ ) incubated with EMT-6 cells for 48 h. The MTT assay results show that the cell survival rate remains above $93 \%$ when the concentration of $\mathrm{Cu}_{\mathrm{x}} \mathrm{S}$-PEG NPs is increased to $100 \mu \mathrm{g} \cdot \mathrm{mL}^{-1}$ (Figure S9), indicating that the $\mathrm{Cu}_{\mathrm{x}} \mathrm{S}$-PEG NPs have no significant cytotoxicity to EMT-6 cells at the tested concentrations. Then, the intracellular conversion performance of $\mathrm{Cu}_{\mathrm{x}} \mathrm{S}$-PEG NPs is investigated on EMT-6 cells after incubating with NPs $\left(50 \mu \mathrm{g} \cdot \mathrm{mL}^{-1}\right)$ for $4 \mathrm{~h}$, and the temperature of cells increases to $43.8^{\circ} \mathrm{C}$ under irradiation with 1064 nm laser $\left(1.0 \mathrm{~W} \cdot \mathrm{cm}^{-2}\right)$ (Figure S10). After incubating with $\mathrm{Cu}_{\mathrm{x}} \mathrm{S}-\mathrm{PEG} \mathrm{NPs}$ for $4 \mathrm{~h}$, 
EMT-6 cells viabilities gradually decrease with increasing concentrations of NPs after irradiation with $1064 \mathrm{~nm}$ laser for $10 \mathrm{~min}\left(1.0 \mathrm{~W} \cdot \mathrm{cm}^{-2}\right)$, remaining only approximately $85 \%, 69.7 \%$ and $54.9 \%$ at concentration of 25,50 and $100 \mu \mathrm{g} \cdot \mathrm{mL}^{-1}$, respectively. Therefore, the $\mathrm{Cu}_{\mathrm{x}} \mathrm{S}$-PEG NPs can be used as NIR-II PTCAs for PTT.

The drug delivery in cells was tested by incubating Dox/Cu $\mathrm{u}_{\mathrm{x}} \mathrm{S}-\mathrm{PEG}$ NPs with EMT-6 cells for different time $(0,1,2$, and $4 \mathrm{~h})$ irradation with or without laser, followed stained by 4',6-diamidino-2-phenylindole (DAPI). The fluorescence signals of Dox are observed in EMT-6 cells treated with Dox/Cu $\mathrm{Cu}_{\mathrm{x}} \mathrm{S}-\mathrm{PEG}$ NPs at different time points (Figure 3D). In addition, the fluorescence intensity of Dox increases obviously in the cells after treating with Dox/Cu $\mathrm{Cu}_{\mathrm{x}} \mathrm{S}$-PEG NPs plus laser, indicating that the NIR-II light can accelerate the release of Dox. As shown in Figure 3E, the mean fluorescence intensity (MFI) of Dox is quantified from images (Figure 3D), which was consistent with results in Figure 3C. Therefore, these results have well demonstrated that $\mathrm{Cu}_{\mathrm{x}} \mathrm{S}$-PEG NPs can be used as NIR-II light-responsive NDDSs for drug delivery in cells.

Next, the NIR-II light-responsive performance of Dox/Cu $\mathrm{Cu}_{\mathrm{x}} \mathrm{S}-\mathrm{PEG} \mathrm{NPs}$ for synergistic chemo-photothermal therapy is studied. EMT-6 cells are treated by free Dox (chemotherapy), Dox/Cu $\mathrm{Cu}_{\mathrm{x}} \mathrm{S}-\mathrm{PEG}$ NPs (chemotherapy), or Dox/Cu $\mathrm{u}_{\mathrm{x}} \mathrm{S}-\mathrm{PEG} \mathrm{NPs}$ plus laser (chemo-photothermal therapy) for cell viability measurement (Figure 3F). At test concentration, the Dox/Cu $\mathrm{Cu}_{\mathrm{x}} \mathrm{S}$-PEG NPs plus laser group shows stronger killing effects than other group. For example, at $5 \mu \mathrm{g} \cdot \mathrm{mL}^{-1}$ of Dox, chemo-photothermal therapy killed $\sim 98.7 \%$ cancer cells, much higher than either free Dox $(\sim 46.1 \%)$ and 
Dox/Cu $\mathrm{Cu}_{\mathrm{x}} \mathrm{S}-\mathrm{PEG}$ NPs $(\sim 36.3 \%)$. Herein, dead/live staining measurement is employed to test the chemo-photothermal therapy effect of Dox/Cu $\mathrm{S}$-PEG NPs on the cancer cells. Six groups including PBS, $\mathrm{Cu}_{\mathrm{x}} \mathrm{S}-\mathrm{PEG}$ NPs, Dox, Dox $/ \mathrm{Cu}_{\mathrm{x}} \mathrm{S}-\mathrm{PEG}$ NPs, $\mathrm{Cu}_{\mathrm{x}} \mathrm{S}$-PEG NPs plus laser, Dox/Cu $\mathrm{Cu}_{\mathrm{x}} \mathrm{S}-\mathrm{PEG}$ NPs plus laser are administrated on the EMT-6 cells. As presented in Figure 3G, almost no cells die (green fluorescence) in groups PBS and $\mathrm{Cu}_{\mathrm{x}} \mathrm{S}$-PEG NPs indicating the no significant cytotoxicity of $\mathrm{Cu}_{\mathrm{x}} \mathrm{S}$-PEG NPs, while the number of dead cells (red fluorescence) with treatment of Dox/Cu $/ u_{x}$ S-PEG NPs plus laser significantly increases. Therefore, the synergistic chemo-photothermal therapy of Dox/Cu $\mathrm{x}_{\mathrm{x}} \mathrm{S}-\mathrm{PEG}$ NPs plus laser displays superior antitumor effect triggered by the NIR-II light.

\section{Detection of DAMPs released from the dying cells}



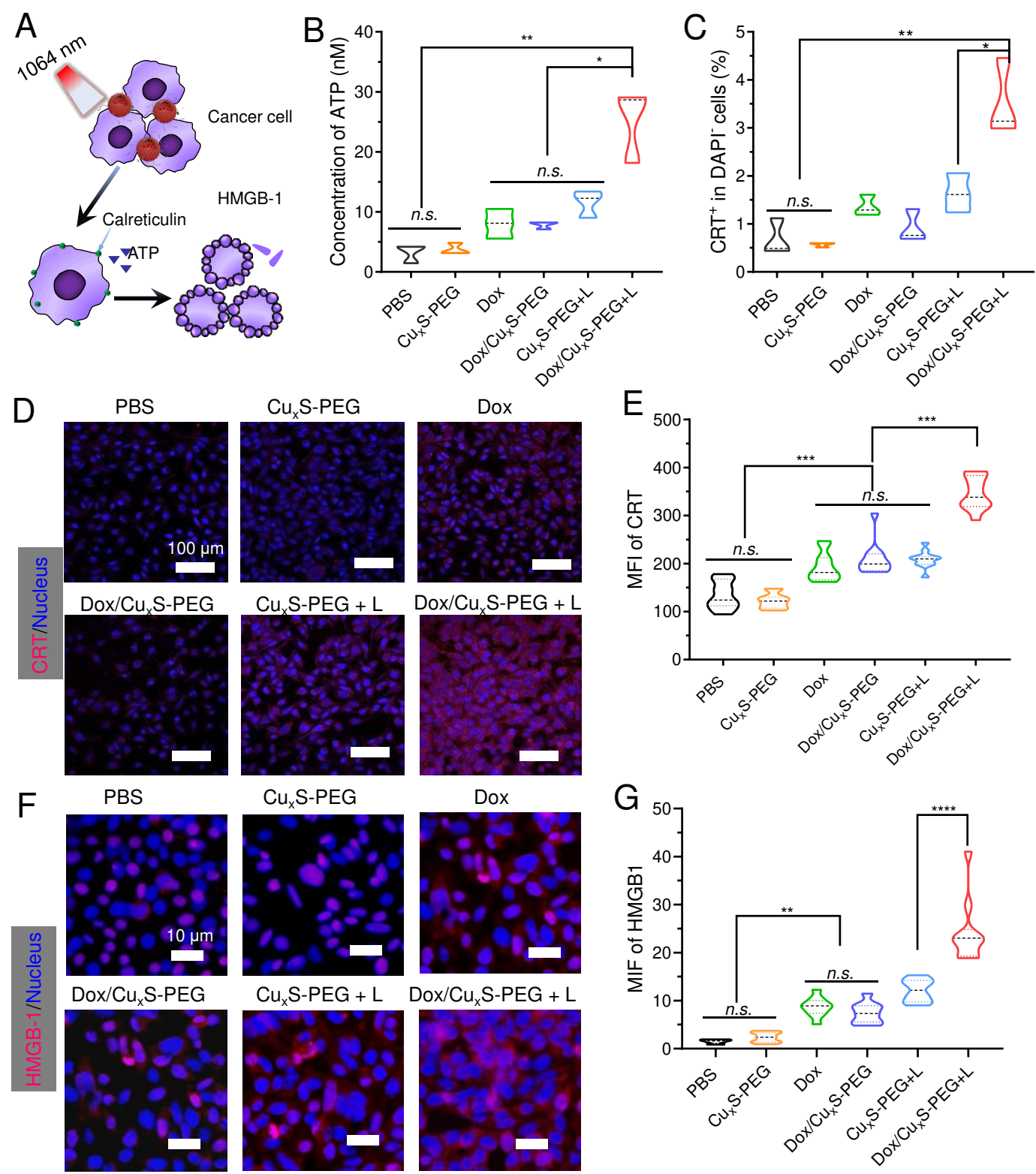

$\mathrm{Cu}_{\mathrm{x}} \mathrm{S}-\mathrm{PEG}$

Dox

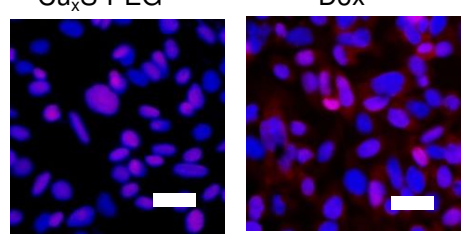

$\mathrm{Cu}_{\mathrm{x}} \mathrm{S}-\mathrm{PEG}+\mathrm{L} \quad \mathrm{Dox} / \mathrm{Cu}_{\mathrm{x}} \mathrm{S}-\mathrm{PEG}+\mathrm{L}$

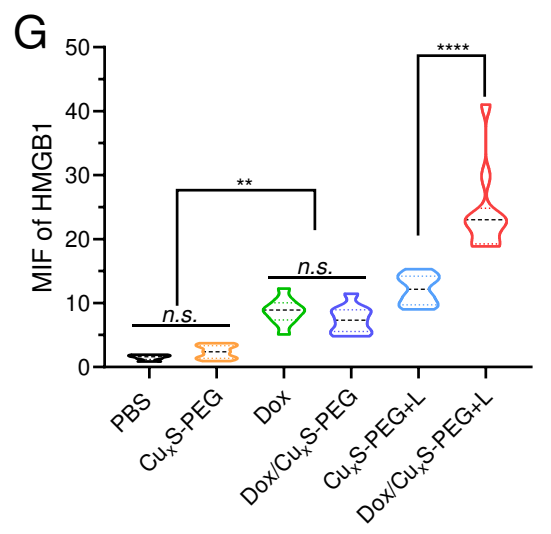

Figure 4. DAMPs released from the dying cells with chemo-photothermal treatment. (A) Schematic illustration of ICD induced by the chemo-photothermal therapy. (B) The concentration of ATP releasing from the EMT-6 cells treated with different groups. (C) Cell-surface exposure of calreticulin (CRT) of DAPI EMT-6 cells after administration with different treatments by flow cytometry analysis. (D) Immunofluorescence microscopy of CRT expression on the cell surface of EMT-6 cells treated with different groups and measured after immunofluorescence staining scale bar: $100 \mu \mathrm{m}$. (E) The MIF of CRT from (D). (F) HMGB-1 release from cell nucleus to cytoplasm of EMT-6 cells treated with different groups and measured after immunofluorescence staining, scale bar: $10 \mu \mathrm{m}$. (G) The MIF of released HMGB-1 from (F). Six groups are respectively PBS, $\mathrm{Cu}_{\mathrm{x}} \mathrm{S}$-PEG NPs, Dox, Dox/Cu $\mathrm{Cu}_{\mathrm{x}} \mathrm{S}-\mathrm{PEG}$ NPs, $\mathrm{Cu}_{\mathrm{x}} \mathrm{S}$-PEG NPs plus laser, and Dox/Cu $\mathrm{x}$-PEG NPs plus laser. Data are shown as mean \pm standard deviation $(\mathrm{n}=3),{ }^{*} \mathrm{p}<0.05, * * \mathrm{p}<0.005, * * * \mathrm{p}<0.001$, and $* * * * \mathrm{p}<$ 0.0001 . 
To date, ICD has been well demonstrated in the chemotherapy or photothermal therapy. As shown in schematic illustration (Figure 4A), DAMPs release from the dying cells after treatment with phototherapy. A "find-me" signal is delivered by the released ATP molecules which cause dendritic cells (DCs) to produce cytokine [44, 45]. In comparison to the groups of PBS, $\mathrm{Cu}_{\mathrm{x}} \mathrm{S}$-PEG NPs, Dox, Dox/Cu $\mathrm{C}$ S-PEG NPs, $\mathrm{Cu}_{\mathrm{x}} \mathrm{S}$-PEG NPs plus laser, we observe a highest level of extracellular ATP at $25.3 \mathrm{nM}$ after treatment with the synergistic chemo-photothermal therapy by using a luciferase-based probe (Figure 4B). Moreover, CRT exposure is a mediator of tumor immunogenicity and potent "eat-me" signal [46]. Flow cytometry measurement reveals that the CRT is most highly expressed after treatment with Dox $/ \mathrm{Cu}_{\mathrm{x}} \mathrm{S}-\mathrm{PEG}$ NPs under $1064 \mathrm{~nm}$ laser irritation, indicating that combination chemotherapy and PTT can more effectively induce the CRT exposure (Figure 4C). The direct fluorescence microscopy observation (Figure 4D) and MIF of CRT from fluorescence image (Figure 4E) further confirm the most significant exposure of CRT after treatment with synergistic chemo-photothermal therapy. To the best of our knowledge, HMGB-1 releasing from cell nucleus in dying cells can trigger inflammation, attract various immune cells and cause DC maturation [47]. In our work, we observe that the treatment of Dox $/ \mathrm{Cu}_{\mathrm{x}} \mathrm{S}$-PEG NPs plus $1064 \mathrm{~nm}$ laser also shows a most significant increase of the translocation of HMGB-1 from nuclei to extracellular space (Figure 4F). The MIF of HMGB-1 in extracellular space from Figure 4F indicates synergistic chemo-photothermal therapy can effectively promote the release of HMGB-1 (Figure 4G). 
Next, in vitro DCs maturation was investigated using Bone marrow-derived dendritic cells (BMDCs). After treated with PBS, Cu $\mathrm{u}_{\mathrm{x}} \mathrm{S}-\mathrm{PEG}$ NPs, Dox, Dox/Cu $\mathrm{Cu}_{\mathrm{x}} \mathrm{S}$-PEG NPs, $\mathrm{Cu}_{\mathrm{x}} \mathrm{S}$-PEG NPs plus laser, and Dox/CuxS-PEG NPs plus laser, the harvested dying EMT-6 cells were incubated with BMDCs for $10 \mathrm{~h}$ at $37{ }^{\circ} \mathrm{C}$ and measured by flow cytometry. A significant percentage of DCs maturation $(38.2 \%)$ is found in the BMDCs incubated with Dox/Cu $/ \mathrm{Cu}_{\mathrm{x}} \mathrm{S}$-PEG NPs plus laser pre-treated cancer cells (Figure S11), which is higher than that of PBS (11.9\%), $\mathrm{Cu}_{\mathrm{x}} \mathrm{S}-\mathrm{PEG}$ NPs (12.4\%), Dox (24.1\%), Dox/Cu $\mathrm{Cu}_{\mathrm{x}} \mathrm{S}-\mathrm{PEG}$ NPs $(23.7 \%)$, and $\mathrm{Cu}_{\mathrm{x}} \mathrm{S}-\mathrm{PEG}$ NPs plus laser $(28.3 \%)$. Therefore, the combination of chemotherapy and PTT can more effectively generate DAMPs in dying cells and benefit the DCs maturation.

\section{The in vivo chemo-photothermal therapy and ICD}



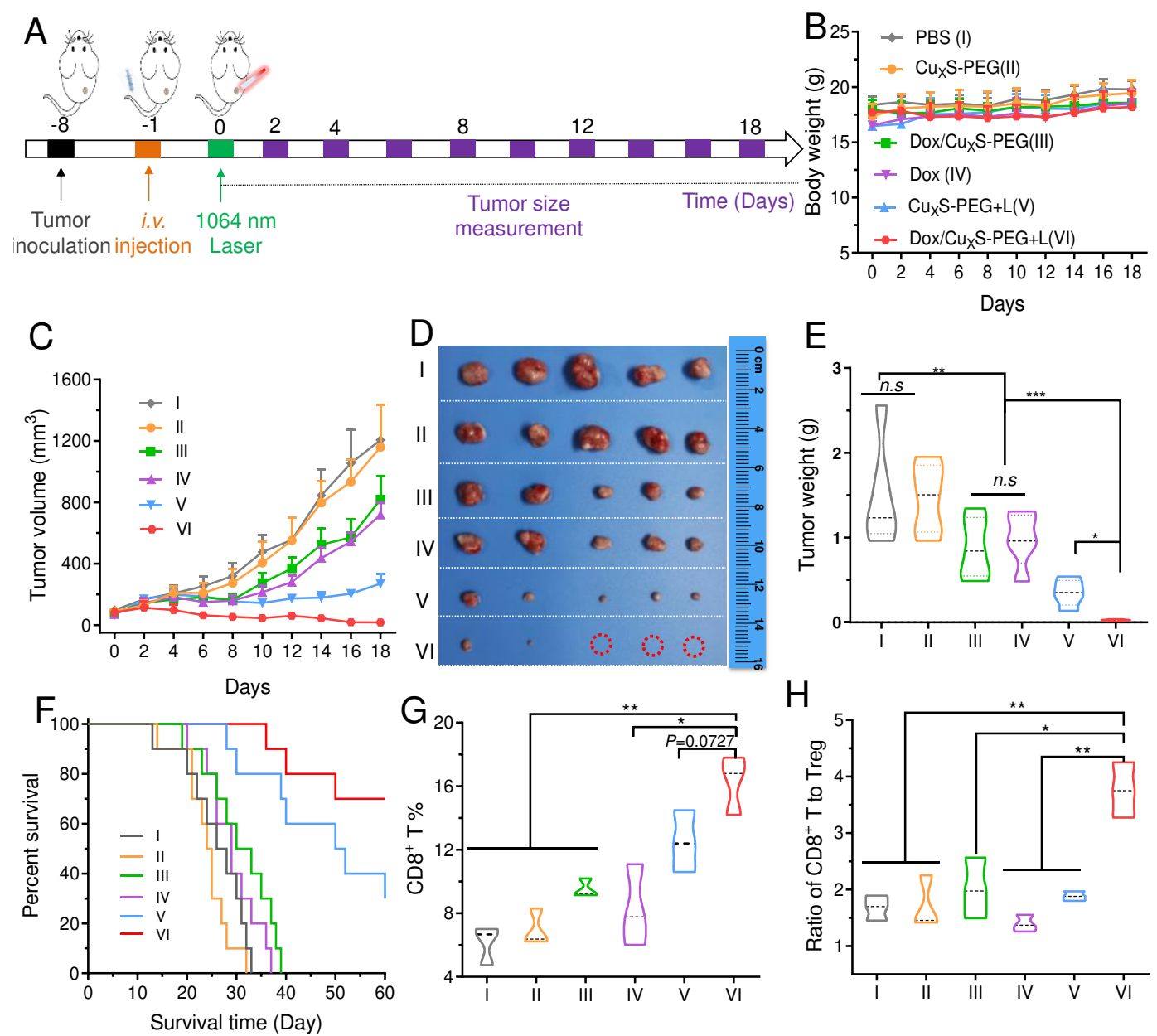

Figure 5. In vivo chemo-photothermal therapy and ICD. (A) Schematic illustration showing the treatment regimen, EMT-6 cells inoculation in the flank of the mouse. The mice $(\mathrm{n}=5)$ received different treatments and irradiated with NIR-II laser for 10 $\min \left(1 \mathrm{~W} \cdot \mathrm{cm}^{-2}\right)$. (B) Mouse body weight, (C) Tumor growth curve, (D) photographs of tumor, (E) Tumor weight of different groups: PBS (I), $\mathrm{Cu}_{\mathrm{x}} \mathrm{S}$-PEG NPs (II), Dox $/ \mathrm{Cu}_{\mathrm{x}} \mathrm{S}$-PEG NPs (III), Dox (IV), $\mathrm{Cu}_{\mathrm{x}} \mathrm{S}$-PEG NPs plus laser (V), and Dox $/ \mathrm{Cu}_{\mathrm{x}} \mathrm{S}$-PEG NPs plus laser (VI). (F) Morbidity-free survival of different groups of mice with EMT-6 tumors after various treatments. After NIR-II photo-treatments for 3 days, percentage of anti-tumor $\mathrm{CD}^{+}$cytotoxic T-lymphocytes cells among leukocytes (G) and $\mathrm{CD}^{+} \mathrm{T}$ cells to Tregs in tumors $(\mathbf{H})$ were analyzed by flow cytometry analysis. Data are shown as mean \pm standard deviation $* \mathrm{p}<0.05, * * \mathrm{p}<0.005, * * * \mathrm{p}<$ 0.001 .

Inspired by the attractive in vitro results, we finally verify the antitumor efficacy in vivo by chemo-photothermal therapy. Before evaluation, we first assessed the pharmacokinetics of $\mathrm{Cu}_{\mathrm{x}} \mathrm{S}$-PEG NPs $\left(10 \mathrm{mg} \cdot \mathrm{kg}^{-1}\right)$ by intravenously injecting to tumor-bearing mice $(\mathrm{n}=3)$. Then, $20 \mu \mathrm{L}$ of blood sample was obtained at 
pre-determined time points $(0,1,2,4,6,12,24$, and $48 \mathrm{~h})$, and ICP-MS analysis displayed that the $\mathrm{Cu}_{\mathrm{x}} \mathrm{S}$-PEG NPs possessed long-term circulation in vivo (Figure S12), owing to the modification of PEG on the surface of NPs. Next, we investigate the biodistributions of $\mathrm{Cu}_{\mathrm{x}} \mathrm{S}$-PEG NPs in the major tissues including heart, liver, spleen, lung, kidney and tumor. The mice were sacrificed at different time $(12,24$, and $48 \mathrm{~h}$ ) after adimistration of $\mathrm{Cu}_{\mathrm{x}} \mathrm{S}$-PEG NPs, and all collected tissues were treated with chloroazotic acid. The ICP-MS measurement indicates that the concentrations of $\mathrm{Cu}_{\mathrm{x}} \mathrm{S}-\mathrm{PEG} \mathrm{NPs}$ in the tumor sites are $\sim 4.3 \%, \sim 7.8 \%$ and $\sim 6.7 \%$ at 12,24 , and $48 \mathrm{~h}$, respectively (Figure S13). Therefore, the time-point at $24 \mathrm{~h}$ after intravenous injection of NPs is suitable for in vivo experiments. To verify in vivo photothermal conversion properties of $\mathrm{Cu}_{\mathrm{x}} \mathrm{S}$-PEG NPs, the typical thermal images of mice under irradiation with the $1064 \mathrm{~nm}$ laser were recorded by the infrared camera (Figure S14). The temperature at tumor sites with the treatments of $\mathrm{Cu}_{\mathrm{x}} \mathrm{S}$-PEG NPs plus laser increases to $45.06{ }^{\circ} \mathrm{C}$ within 5 min (Figure S15), while the temperature of PBS group is silghtly increased. These results reveal that the enhanced permeability and retention (EPR) effect induced $\mathrm{Cu}_{\mathrm{x}} \mathrm{S}$-PEG NPs accumulating into the the tumor sites passively.

Next, we investigate the antitumor efficacy of the synergistic chemo-photothermal therapy based on the $\mathrm{Cu}_{\mathrm{x}} \mathrm{S}$-PEG NPs triggered by NIR-II laser. As the schematic illustration shown in the Figure 5A, when the tumors were growing to $\sim 100 \mathrm{~mm}^{3}$, six groups $(\mathrm{n}=5)$ of the EMT-6 tumor bearing mice were received different treatments as follows: (I) PBS as control, (II) $\mathrm{Cu}_{\mathrm{x}} \mathrm{S}$-PEG NPs (dose of 10 $\mathrm{mg} \cdot \mathrm{kg}^{-1}$ ), (III) Dox $/ \mathrm{Cu}_{\mathrm{x}} \mathrm{S}-\mathrm{PEG}$ NPs, (IV) only Dox, (V) $\mathrm{Cu}_{\mathrm{x}} \mathrm{S}$-PEG NPs plus laser, 
and (VI) Dox $/ \mathrm{Cu}_{\mathrm{x}} \mathrm{S}$-PEG NPs plus laser $\left(1 \mathrm{~W} \cdot \mathrm{cm}^{-2}\right.$ for $\left.10 \mathrm{~min}\right)$. Subsequently, the mice weight and tumor volume were monitored every two days. The body weight of mice in all groups shows no remarkable undulation during the therapeutic process (Figure 5B), which indicates the security of NIR(II)-induced synergistic chemo-photothermal therapy. Moreover, the groups (V) and (VI) efficiently inhibite tumor growth by $\sim 76.8 \%$ and $\sim 98.5 \%$ respectively, after irradiation treatment with $1064 \mathrm{~nm}$ laser (Figure 5C). Meanwhile, on the 18th day after the first treatments, the the photos (Figure 5D) and weight measurement (Figure 5E) of the excised tumors from sacrificial mice of all groups verify that Dox/Cu $\mathrm{Cu}_{\mathrm{x}} \mathrm{S}$-PEG NPs plus laser group can realize more efficient tumor suppression than either PTT or chemotherapy alone, which is consistent with cellular reuslts. Remarkably, all the tumors in Dox/Cu $\mathrm{Cu}_{\mathrm{x}} \mathrm{S}-\mathrm{PEG}$ NPs plus laser group (VI) are alomst completely eliminated at the end of therapy (Figure S16). In contrast, the groups (I) and (II) show negligible influence on the tumor growth, and slight inhibition effect is observed in Dox/Cu $\mathrm{Cu}_{\mathrm{x}} \mathrm{S}-\mathrm{PEG} \mathrm{NPs}$ and Dox groups. To assess the therapeutic effect, the excised tumors were sliced and stained with H\&E (Figure S17) and TUNEL staining (Figure S18), which demonstrated that Group VI displayed much severer necrosis of tumor cells than the other groups. To further evaluate the therapeutic outcomes of $\mathrm{Dox} / \mathrm{Cu}_{\mathrm{x}} \mathrm{S}$-PEG NPs plus laser based on chemo-photothermal therapy, the survival experiment was carried out on the EMT-6 tumors bearing mice after treated with different groups. We find that seven of ten tumors bearing mice can survive for 60 days after treated Dox/ $\mathrm{Cu}_{\mathrm{x}} \mathrm{S}$-PEG NPs plus laser, in marked contrast to mice in the PBS, $\mathrm{Cu}_{\mathrm{x}} \mathrm{S}-\mathrm{PEG}$ NPs, 
Dox/CuxS-PEG NPs, and only Dox groups in which all die within 30-40 days (Figure 5F). These experimental results indicate that the breast cancer could be effectively inhibited by chemo-photothermal therapy.

Next, we aslo investigated the immune response from ICD after treatments with chemo-photothermal therapy, which can trigger cytotoxic T-lymphocytes and induce anti-tumor immunity [48]. In our experiments, the EMT-6 tumor bearing mice were divided into six groups $(\mathrm{n}=5)$ and administrated with different treatments including PBS (I), $\mathrm{Cu}_{\mathrm{x}} \mathrm{S}$-PEG NPs (II), Dox/Cu $\mathrm{Cu}_{\mathrm{x}} \mathrm{S}$-PEG NPs (III), Dox (IV), Cu $\mathrm{Cu}_{\mathrm{x}} \mathrm{S}$-PEG NPs plus laser $(\mathrm{V})$, and Dox/Cu $\mathrm{C}$ S-PEG NPs plus laser (VI). At $72 \mathrm{~h}$ after treatments with different groups, the PBS and $\mathrm{Cu}_{\mathrm{x}} \mathrm{S}$-PEG NPs with i.v. injection alone failed to promote $\mathrm{CD}^{+}$cytotoxic T-lymphocytes infiltration into tumors. On the contrary, the percentage of $\mathrm{CD}^{+}$cytotoxic T-lymphocytes in tumors of mice after the Dox $/ \mathrm{Cu}_{\mathrm{x}} \mathrm{S}-\mathrm{PEG}$ NPs plus laser significantly increases to $\sim 16.3 \%$, which is higher than that in Dox $(\sim 8.3 \%)$ and $\mathrm{Cu}_{\mathrm{x}} \mathrm{S}-\mathrm{PEG}$ NPs plus laser $(\sim 12.5 \%)$ (Figure 5G). The regulatory $\mathrm{T}$ cells (Tregs) can hamper effective anti-tumor immune responses. It is found that the Dox/Cu $\mathrm{Cu}_{\mathrm{x}} \mathrm{S}$-PEG NPs based chemo-photothermal therapy can significantly reduce the percentages of Tregs in the tumors (Figure S19). Therefore, both $\mathrm{CD}^{+} /$Treg ratio are greatly enhanced in tumors after the treatment of Dox $/ \mathrm{Cu}_{\mathrm{x}} \mathrm{S}$-PEG NPs based chemo-photothermal therapy (Figure 5H). From the abovementioned results, the Dox/Cu $\mathrm{Cu}_{\mathrm{x}} \mathrm{S}$-PEG NPs based chemo-photothermal therapy can more effectively induce ICD to elicit an adaptive immune response. 


\section{Conclusion}

In summary, we successfully develop a hollow structure $\mathrm{Cu}_{\mathrm{x}} \mathrm{S}$-PEG NPs for NIR-II light-responsive drug delivery and synergistic chemo-photothermal cancer therapy, which can effectively induce ICD. The Dox moleculars can be loaded into the $\mathrm{Cu}_{\mathrm{x}} \mathrm{S}$-PEG NPs, displaying a controllable drug release triggered by NIR-II laser irradiation. The synergistic chemo-photothermal strategy cab more effectively trigger ICD than that of single treatment. In vitro and in vivo results demonstrated that the synergistic chemo-photothermal therapeutic efficacy based on the Dox $/ \mathrm{Cu}_{\mathrm{x}} \mathrm{S}-\mathrm{PEG}$ NPs is superior to that of monotherapy. Additionally, the synergistic chemo-photothermal therapy can promote $\mathrm{CD} 8^{+}$cytotoxic T-lymphocytes infiltration into tumours, which will provide an effective approach to accomplish a photo-immunological response and elicit effective anti-tumor immunotherapy. Such $\mathrm{Cu}_{\mathrm{x}} \mathrm{S}$-PEG NPs may encourages the development of NIR-II light-responsive NDDSs for further biomedical utility. 


\section{Methods}

\section{Materials}

$\mathrm{Cu}\left(\mathrm{NO}_{3}\right)_{2}$, Polyvinylpyrrolidone (PVP, K30), hydrazine hydrate, dimethylsulfoxide, sodium sulphide $\left(\mathrm{Na}_{2} \mathrm{~S}\right)$, doxorubicin hydrochloride, methylene chloride, diethyl ether, 3-(4,5-dimethylthiazol-2-yl)-2,5-diphenyltetrazolium bromide (MTT), glycol, 4',6-diamidino-2-phenylindole (DAPI), lipoic acid, polyethylene glycol ( $\mathrm{PEG}_{5 \mathrm{k}}$ ), 1-(3-Dimethylaminopropyl)-3-ethylcarbodiimide hydrochloride (EDC), and 4-dimethylaminopyridine (DMAP) were all purchased from Aladdin reagent Co. LTD. Dulbecco's modified eagle medium (DMEM) and Fetal bovine serum (FBS) were bought from Gibco BRL (Eggenstein, Germany). Deionized water $(\sim 18.2 \mathrm{M} \Omega \cdot \mathrm{cm})$ obtained from a Milli-Q Water Purification System was used in all the experiments.

\section{Synthesis of hollow $\mathrm{Cu}_{\mathrm{x}} \mathrm{S}$ nanospheres}

First, $50 \mathrm{mg} \mathrm{Cu}\left(\mathrm{NO}_{3}\right)_{2}$ and $1 \mathrm{~g}$ PVP were added into a mixture of $50 \mathrm{~mL}$ deionized water and glycol $(\mathrm{V}: \mathrm{V}=1: 1)$ to form homogeneous solution under vigorous stirring. Then, hydrazine hydrate $(30 \mu \mathrm{L})$ was immediately added into the above solution keeping stirring for $5 \mathrm{~min}$. Subsequently, the $\mathrm{Cu}_{2} \mathrm{O}$ NPs were collected by centrifugation and washed several times with deionized water.

Next, the obtained $\mathrm{Cu}_{2} \mathrm{O}$ NPs were resuspended in the $10 \mathrm{~mL}$ of DI water, and 1 $\mathrm{mL} \mathrm{Na} \mathrm{S}_{2} \mathrm{~S}$ aqueous solution $(0.5 \mathrm{M})$ was introduced into $\mathrm{Cu}_{2} \mathrm{O}$ NPs suspension keeping stirring for $30 \mathrm{~min}$ to prepare hollow $\mathrm{Cu}_{\mathrm{x}} \mathrm{S}$ NPs. Finally, the $\mathrm{Cu}_{\mathrm{x}} \mathrm{S}$ NPs was harvested by centrifugation and washed several times with deionized water.

\section{Synthesis of $\mathrm{Cu}_{\mathrm{x}} \mathrm{S}$-PEG NPs}


The LA-PEG was prepared according to our previous report [49]. Typically, $5 \mathrm{~g}$ $\mathrm{mPEG}_{5 \mathrm{k}}$ was dissolved in $20 \mathrm{~mL}$ dichloromethane. After fully dissolved, lipoic acid $(1.0 \mathrm{~g})$, EDC $(1.0 \mathrm{~g})$, and DMAP $(0.4 \mathrm{~g})$ were introuduced in $20 \mathrm{~mL}$ of dichloromethane and activated in an ice bath for $3 \mathrm{~h}$. The mixture further reacted for $72 \mathrm{~h}$, and then the products were precipitated with diethyl ether for three times and dried overnight in vacuo to obtain LA-PEG.

Next, the hollow $\mathrm{Cu}_{\mathrm{x}} \mathrm{S}$ NPs were incubated with LA-PEG solution $\left(10 \mathrm{mg} \cdot \mathrm{mL}^{-1}\right)$ for $24 \mathrm{~h}$ in room, and the $\mathrm{Cu}_{\mathrm{x}} \mathrm{S}$-PEG NPs were collected by centrifugation to remove redundant LA-PEG.

\section{Study of the NIR-II photothermal effect}

To explore the photothermal conversion effect of the synthesized $\mathrm{Cu}_{\mathrm{x}} \mathrm{S}$-PEG NPs dispersion containing different concentrations $\left(0,50,100\right.$, and $\left.200 \mu \mathrm{g} \cdot \mathrm{mL}^{-1}\right)$ were irradiated by a $1064 \mathrm{~nm}$ laser (Xi'an Minghui Optoelectronic Technology) at a power density of $1 \mathrm{~W} \cdot \mathrm{cm}^{-2}$ for $5 \mathrm{~min}$. The temperature at each time point was recorded by the NIR thermal imaging camera (IC17320, Infrared Camera Inc).

The photothermal stability of $\mathrm{Cu}_{\mathrm{x}} \mathrm{S}$-PEG NPs $\left(50 \mu \mathrm{g} \cdot \mathrm{mL}^{-1}\right)$ was measured by irradiating with a $1064 \mathrm{~nm}$ laser $\left(1.0 \mathrm{~W} \cdot \mathrm{cm}^{-2}\right)$ for $3 \mathrm{~min}$, followed by shuting off laser for $3 \mathrm{~min}$. The laser was applied to on/off with an interval of $3 \mathrm{~min}$ for four cycles.

To further evaluate the photothermal response of $\mathrm{Cu}_{\mathrm{x}} \mathrm{S}$-PEG NPs in cells, EMT-6 cells were incubated with $\mathrm{Cu}_{\mathrm{x}} \mathrm{S}$-PEG NPs $\left(50 \mu \mathrm{g} \cdot \mathrm{mL}^{-1}\right)$ in DMEM for four hours. Then the collected cells were irradiated by a $1064 \mathrm{~nm}$ laser $\left(1.0 \mathrm{~W} \cdot \mathrm{cm}^{-2}\right)$ for $10 \mathrm{~min}$. Meanwhile, the photothermal heating curves were recorded by the NIR thermal 
imaging camera.

EMT-6 tumor-bearing mice were respectively intravenously injected with $\mathrm{Cu}_{\mathrm{x}} \mathrm{S}$-PEG NPs $\left(10 \mathrm{mg} \cdot \mathrm{kg}^{-1}\right)$ and PBS (as control group). After 24 hours, all mice were irradiated with a $1064 \mathrm{~nm}$ laser $\left(1 \mathrm{~W} \cdot \mathrm{cm}^{-2}\right)$ for $6 \mathrm{~min}$ in the tumor site. The thermal images and temperature at tumor site were recorded simultaneously with infrared thermal camera.

\section{Drug loading and releasing experiments}

Typically, different amount of Dox was mixed with $\mathrm{Cu}_{\mathrm{x}} \mathrm{S}$ NPs $\left(1 \mathrm{mg} \cdot \mathrm{mL}^{-1}\right)$ dispersion in PBS under stirring at ambient temperature for $24 \mathrm{~h}$, followed by the addition of the LA-PEG solution $\left(10 \mathrm{mg} \cdot \mathrm{mL}^{-1}\right)$ for further incubating for $24 \mathrm{~h}$. The Dox-loaded Dox $/ \mathrm{Cu}_{\mathrm{x}} \mathrm{S}$-PEG NPs were obtianed by centrifugation to discard the unencapsulated Dox and excess PEG in the supernatant. To evaluate the drug loading capacity of $\mathrm{Cu}_{\mathrm{x}} \mathrm{S}$-PEG NPs, the supernatant after centrifugation was carefully collected for the UV-Vis spectrum measurement. The Dox loading capacity was calculated corresponding to standard calibration curve.

For the stimuli-responsive Dox release study, Dox/Cu $\mathrm{S}$-PEG NPs dispersions $\left(200 \mu \mathrm{g} \cdot \mathrm{mL}^{-1}\right)$ with $\mathrm{pH}=6.0$ and 7.4 with or without irradiation of NIR-II laser were tested at selected time points (i.e., 0, 1, 2, 4, 6, 12, and $24 \mathrm{~h}$ ).

To study the intracellular drug delivery of the Dox/Cu $\mathrm{S}$-PEG NPs, EMT-6 cells were incubated with Dox/ $\mathrm{Cu}_{\mathrm{x}} \mathrm{S}$-PEG NPs dispersion for $0,1,2$, and $4 \mathrm{~h}$ with or without 5 min NIR-II laser irradiation. After the treatments, the cells were measured by the inverted fluorescence microscope for different time point. 


\section{In Vitro chemotherapy and chemo-photothermal therapy}

To study the chemotherapy and chemo-photothermal effect of the Dox/Cu $\mathrm{Cu}_{\mathrm{x}} \mathrm{S}-\mathrm{PEG}$ NPs in cancer cells, EMT-6 cells $\left(3 \times 10^{3}\right)$ were seeded in 96-well plate and treated with the free Dox, Dox $/ \mathrm{Cu}_{\mathrm{x}} \mathrm{S}-\mathrm{PEG}$, and Dox $/ \mathrm{Cu}_{\mathrm{x}} \mathrm{S}-\mathrm{PEG}+$ laser, respectively. The concentration of free Dox was normalized to be equivalent to the loaded Dox in the $\mathrm{Cu}_{\mathrm{x}} \mathrm{S}$-PEG NPs. After the treatments, the cell viability of cancer cells was measured by MTT assay.

\section{In vivo chemo-photothermal therapy}

When the tumor volumes were about $100 \mathrm{~mm}^{3}$, the mice were randomly divided into the following six groups $(\mathrm{n}=5)$ : (I) Control (PBS), (II) $\mathrm{Cu}_{\mathrm{x}} \mathrm{S}$-PEG NPs, (III) Dox $/ \mathrm{Cu}_{\mathrm{x}} \mathrm{S}$-PEG NPs, (IV) free Dox only, (V) $\mathrm{Cu}_{\mathrm{x}} \mathrm{S}$-PEG NPs + Laser, and (VI) Dox $/ \mathrm{Cu}_{\mathrm{x}} \mathrm{S}$-PEG NPs + Laser. After tail intravenous injection with free Dox, $\mathrm{Cu}_{\mathrm{x}} \mathrm{S}$-PEG NPs and Dox/Cu $\mathrm{C}$ S-PEG NPs dispersions, the mice in group (V) and (VI) were exposed to $1064 \mathrm{~nm}$ laser $\left(1.0 \mathrm{~W} \cdot \mathrm{cm}^{-2}\right)$ for $10 \mathrm{~min}$. During the irradiation, the tumor temperature was monitored by the IR thermal camera. After laser irradiation, the tumor length and width of the mice were measured every 2 days. The tumor volume was calculated according to the following formula: $($ tumor volume $)=($ length $)$ $\times(\text { width })^{2} / 2$. At the end of experiment, the tumor tissues were excised and weighed. Finally, the harvested tumor tissues were fixed in the paraformaldehyde solution, and then the paraffin-embedded tumors were sectioned for the hematoxylin and eosin (H\&E) and terminal deoxynucleotidyl transferase mediated dUTP nick-end labeling (TUNEL) staining staining before the observation under a fluorescence microscope. 


\section{List of abbreviations}

PTT: photothermal therapy; ICD: immunogenic cell death; DAMPs: damage-related molecular patterns; NDDSs: nanocarrier-based drug delivery systems; PTCAs: photothermal conversion agents; NPs: nanoparticles; Dox: doxorubicin; ATP: adenosine triphosphate; CRT: calreticulin; HMGB-1: high mobility group box-1; PEG-LA: glycol-lipoic acid; TEM: transmission electron microscopy; SEM: scanning electron microscopy; PXRD: powder X-ray diffraction; MFI: mean fluorescence intensity; DCs: dendritic cells; ICP-MS: inductively coupled plasma mass spectrometry; H\&E: hematoxylin and eosin; TUNEL: terminal deoxynucleotidyl transferase mediated dUTP nick-end labeling.

\section{Declarations}

\section{Ethics approval and consent to participate}

All animals received were cared in compliance with the guidelines outlined in the Guide for the Care and Use of Laboratory Animals, and all procedures were approved by the Guangdong Second Provincial General Hospital Animal Care and Use Committee.

\section{Availability of data and materials}

All data generated or analysed during this study are included in this published article [and its supplementary information files].

\section{Competing Interests}

The authors have declared that no competing interest exists.

\section{Funding}


This work is supported by the National Natural Science Foundation of China (NSFC) (51903162 and U1903120), Science Foundation of Guangdong Second Provincial General hospital (YN2018-001), Doctoral Workstation of Guangdong Second Provincial (2019BSG2024), Key Research and Development Program of Anhui Province (202004J07020015), and Guangzhou Science and Technology Plan Project (202102020646).

\section{Authors' contributions}

L Hang, L Wu and D Men: Methodology, Project administration, Writing - original draft. H Wen and X Tang: Methodology, Investigation. C Zhou and X Ma: Methodology, Visualization. L Hang and G Jiang: Writing - review \& editing, Validation, Supervision.

\section{Acknowledgements}

We thank the staff of the Medical Research Center of Guangdong Second Provincial General Hospital for technical support.

\section{References}

[1] Chen Q, Xu L, Liang C, Wang C, Peng R, Liu Z. Photothermal therapy with immune-adjuvant nanoparticles together with checkpoint blockade for effective cancer immunotherapy. Nat Commun. 2016; 7: 1-13.

[2] Lu K, He C, Guo N, Chan C, Ni K, Weichselbaum RR, et al. Chlorin-based nanoscale metal-organic framework systemically rejects colorectal cancers via synergistic photodynamic therapy and checkpoint blockade immunotherapy. J Am Chem Soc. 2016; 138: 12502-10.

[3] Duan X, Chan C, Lin W. Nanoparticle-mediated Immunogenic Cell Death Enables and Potentiates Cancer Immunotherapy. Angew Chem Int Ed. 2019; 58: 670-80.

[4] Wang M, Song J, Zhou F, Hoover AR, Murray C, Zhou B, et al. Nir-triggered 
phototherapy and immunotherapy via an antigen-capturing nanoplatform for metastatic cancer treatment. Adv Sci. 2019; 6: 1802157.

[5] Wang C, Xu L, Liang C, Xiang J, Peng R, Liu Z. Immunological responses triggered by photothermal therapy with carbon nanotubes in combination with antiCTLA-4 therapy to inhibit cancer metastasis. Adv Mater. 2014; 26: 8154-62.

[6] Yu GT, Rao L, Wu H, Yang LL, Bu LL, Deng WW, et al. Myeloid-Derived Suppressor Cell Membrane-Coated Magnetic Nanoparticles for Cancer Theranostics by Inducing Macrophage Polarization and Synergizing Immunogenic Cell Death. Adv Funct Mater. 2018; 28: 1801389.

[7] Song W, Kuang J, Li C-X, Zhang M, Zheng D, Zeng X, et al. Enhanced immunotherapy based on photodynamic therapy for both primary and lung metastasis tumor eradication. ACS Nano. 2018; 12: 1978-89.

[8] Majumder J, Taratula O, Minko T. Nanocarrier-based systems for targeted and site specific therapeutic delivery. Adv Drug Deliver Rev. 2019;144: 57-77.

[9] Xue Y, Bai H, Peng B, Fang B, Baell J, Li L, et al. Stimulus-cleavable chemistry in the field of controlled drug delivery. Chem Soc Rev. 2021; 50: 4872-931.

[10] Dou Y, Li C, Li L, Guo J, Zhang J. Bioresponsive drug delivery systems for the treatment of inflammatory diseases. J Control Release. 2020; 327: 641-66.

[11] Jiang T, Xu G, Chen G, Zheng Y, He B, Gu Z. Progress in transdermal drug delivery systems for cancer therapy, Nano Res. 2020; 13: 1810-24

[12] Hang L, Li H, Zhang T, Men D, Zhang C, Gao P, et al. Au@Prussian Blue Hybrid Nano-material Synergy with Chemotherapeutic Drug for Tumor Diagnosis and Chemo-Dynamic Therapy. ACS Appl Mater Interfaces. 2019; 11: 39493-502.

[13] Li L, Yang Z, Chen X. Recent Advances in Stimuli-Responsive Platforms for Cancer Immunotherapy. Accounts Chem Res. 2020; 53: 2044-2054.

[14] Liu G, Lovell J, Zhang L, Zhang Y. Stimulus-Responsive Nanomedicines for Disease Diagnosis and Treatment. Int J Mol Sci. 2020; 21: 6380

[15] Luo L, Xu F, Peng H, Luo Y, Tian X, Battaglia G, et al. Stimuli-responsive polymeric prodrug-based nanomedicine delivering nifuroxazide and doxorubicin against primary breast cancer and pulmonary metastasis. J Control Release. 2020; 318: 
124-35.

[16] Zhou Y, Ye H, Chen Y, Zhu R, Yin L. Photo-Responsive Drug/Gene Delivery Systems, Biomacromolecules 2018; 19: 1840.

[17] Li Z, Hu Y, Miao Z, Xu H, Li C, Zhao Y, et al. Dual-stimuli responsive bismuth nanoraspberries for multimodal imaging and combined cancer therapy. Nano Lett. 2018; 18: 6778-88.

[18] Dong X, Yin W, Zhang X, Zhu S, He X, J. Yu, Xie J, et al. Intelligent $\mathrm{MoS}_{2}$ nanotheranostic for targeted and enzyme-/pH-/NIR-responsive drug delivery to overcome cancer chemotherapy resistance guided by PET imaging. ACS Appl Mater Interfaces. 2018; 10: 4271-84.

[19] Huang F, Liao W-C, Sohn YS, Nechushtai R, Lu C-H, Willner I. Light-responsive and pH-responsive DNA microcapsules for controlled release of loads. J Am Chem Soc. 2016; 138: 8936-45.

[20] Zhang Y, Zhang Y, Song G, He Y, Zhang X, Liu Y, et al. A DNA-Azobenzene nanopump fFueled by upconversion luminescence for controllable intracellular drug release. Angew Chem Int Ed. 2019; 58: 18207-11.

[21] Zhu K, Liu G, Hu J, Liu S. Near-infrared light-activated photochemical internalization of reduction-responsive polyprodrug vesicles for synergistic photodynamic therapy and chemotherapy. Biomacromolecules. 2017; 18: 2571-82.

[22] Xu Z, Zhang Y, Zhou W, Wang L, Xu G, Ma M, Yang, C. NIR-II-activated biocompatible hollow nanocarbons for cancer photothermal therapy. J Nanobiotechnol. 2021; 19: 1-11.

[23] Jiang Y, Cui D, Fang Y, Zhen X, Pramanik M, Upputuri PK, et al. Amphiphilic semiconducting polymer as multifunctional nanocarrier for fluorescence/photoacoustic imaging guided chemo-photothermal therapy, Biomaterials. 2017; 145: 168-77.

[24] Zhao X, Yang C-X, Chen L-G, Yan X-P. Dual-stimuli responsive and reversibly activatable theranostic nanoprobe for precision tumor-targeting and fluorescence-guided photothermal therapy. Nat Commun. 2017; 8: 1-9.

[25] Song XR, Li SH, Dai J, Song L, Huang G, Lin R, et al. Polyphenol-inspired 
facile construction of smart assemblies for ATP-and $\mathrm{pH}$-responsive tumor MR/Optical imaging and photothermal therapy. Small. 2017; 13: 1603997.

[26] Wang X, Xuan Z, Zhu X, Sun H, Li J, Xie Z. Near-infrared photoresponsive drug delivery nanosystems for cancer photo-chemotherapy. J Nanobiotechnol. 2020;18: $1-19$.

[27] Zhang X, Wang S, Cheng G, Yu P, Chang J, Chen X. Cascade drug-release strategy for enhanced anticancer therapy. Matter. 2021; 4: 26-53.

[28] Shen S, Ding B, Zhang S, Qi X, Wang K, Tian J,et al. Near-infrared light-responsive nanoparticles with thermosensitive yolk-shell structure for multimodal imaging and chemo-photothermal therapy of tumor. Nanomed Nanotechnol. 2017; 13: 1607-16.

[29] Meng Z, Wei F, Wang R, Xia M, Chen Z, Wang H, et al. NIR-laser-switched in vivo smart nanocapsules for synergic photothermal and chemotherapy of tumors. Adv Mater. 2016; 28: 245-53.

[30] Alkilany AM, Thompson LB, Boulos SP, Sisco PN, Murphy CJ. Gold nanorods: their potential for photothermal therapeutics and drug delivery, tempered by the complexity of their biological interactions. Adv Drug Deliver Rev. 2012; 64: 190-9.

[31] Miao D, Yu Y, Chen Y, Liu Y, Su G. Facile Construction of i-Motif DNA-Conjugated Gold Nanostars as Near-Infrared and pH Dual-Responsive Targeted Drug Delivery Systems for Combined Cancer Therapy. Mol Pharmaceutics. 2020; 17: 1127-38.

[32] Zhou ZH, Liang SY, Zhao TC, Chen XZ, Cao XK, Qi M, Zhong LP. Overcoming chemotherapy resistance using $\mathrm{pH}$-sensitive hollow $\mathrm{MnO}_{2}$ nanoshells that target the hypoxic tumor microenvironment of metastasized oral squamous cell carcinoma. $\mathrm{J}$ Nanobiotechnol. 2021; 19: 1-14.

[33] Tian R, Ke C, Rao L, Lau J, Chen X. Multimodal stratified imaging of nanovaccines in lymph nodes for improving cancer immunotherapy. Adv. Drug Deliver Rev. 2020; 161: 145-160.

[34] Li Volsi A, Scialabba C, Vetri V, Cavallaro G, Licciardi M, Giammona G. Near-infrared light responsive folate targeted gold nanorods for combined 
photothermal-chemotherapy of osteosarcoma. ACS Appl Mater Interfaces 2017; 9: 14453-69.

[35] Du Y, Xia L, Jo A, Davis RM, Bissel P, Ehrich MF, et al. Synthesis and evaluation of doxorubicin-loaded gold nanoparticles for tumor-targeted drug delivery. Bioconjugate Chem. 2018; 29: 420-30.

[36] Wang H, Di J, Sun Y, Fu J, Wei Z, Matsui H, et al. Biocompatible PEGchitosan@carbon dots hybrid nanogels for two-photon fluorescence imaging, nearinfrared light $/ \mathrm{pH}$ dual-responsive drug carrier, and synergistic therapy. Adv Funct Mater. 2015; 25: 5537-47.

[37] Cheng L, Wang C, Feng L, Yang K, Functional nanomaterials for phototherapies of cancer. Chem Rev. 2014; 114: 10869-939.

[38] Song S, Chong Y, Fu H, Ning X, Shen H, Zhang Z. HP- $\beta-C D$ functionalized $\mathrm{Fe}_{3} \mathrm{O}_{4} / \mathrm{CNPs}$-based theranostic nanoplatform for $\mathrm{ph} /$ nir responsive drug release and mr/nirfl imaging-guided synergetic chemo/photothermal therapy of tumor. ACS Appl Mater Interfaces. 2018; 10: 33867-78.

[39] Ku G, Zhou M, Song S, Huang Q, Hazle J, Li C. Copper sulfide nanoparticles as a new class of photoacoustic contrast agent for deep tissue imaging at $1064 \mathrm{~nm}$. ACS Nano. 2012; 6: 7489-96.

[40] Han L, Zhang Y, Chen X-W, Shu Y, Wang J-H. Protein-modified hollow copper sulfide nanoparticles carrying indocyanine green for photothermal and photodynamic therapy. J Mater Chem B. 2016; 4: 105-12.

[41] Guo L, Panderi I, Yan D, Szulak K, Lu W. A comparative study of hollow copper sulfide nanoparticles and hollow gold nanospheres on degradability and toxicity. ACS Nano. 2013; 7: 8780 .

[42] Zhang C, Men D, Zhang T, Yu Y, Xiang J, Jiang G, et al. Nanoplatforms with remarkably enhanced absorption in the second biological window for effective tumor thermoradiotherapy. ACS Appl Mater Interfaces. 2019; 12: 2152-61.

[43] Fang Y, Luan D, Chen Y, Gao S, Lou XW. Synthesis of copper-substituted $\mathrm{CoS}_{2} @ \mathrm{CuxS}$ double-shelled nanoboxes by sequential ion exchange for efficient sodium storage. Angew Chem. 2020;132(7):2666-70. 
[44] Garg AD, Krysko DV, Verfaillie T, Kaczmarek A, Ferreira GB, Marysael T, et al. A novel pathway combining calreticulin exposure and ATP secretion in immunogenic cancer cell death. EMBO J. 2012; 31: 1062-79.

[45] Aymeric L, Apetoh L, Ghiringhelli F, Tesniere A, Martins I, Kroemer G, et al. Tumor cell death and ATP release prime dendritic cells and efficient anticancer immunity. Cancer Res. 2010; 70: 855-8.

[46] Obeid M, Tesniere A, Ghiringhelli F, Fimia GM, Apetoh L, Perfettini JL, et al. Calreticulin exposure dictates the immunogenicity of cancer cell death. Nat Med. 2007; 13: 54-61.

[47] Sang W, Zhang Z, Dai Y, Chen X. Recent advances in nanomaterial-based synergistic combination cancer immunotherapy. Chem Soc Rev. 2019; 48: 3771-810. [48] Kepp O, Senovilla L, Vitale I, Vacchelli E, Adjemian S, Agostinis P, et al. Consensus guidelines for the detection of immunogenic cell death. Oncoimmunology. 2014; 3: e955691.

[49] Zhang C, Men D, Zhang T, Yu Y, Xiang J, Jiang G, et al. Nanoplatforms with remarkably enhanced absorption in the second biological window for effective tumor thermoradiotherapy. ACS Appl Mater Interfaces. 2019; 12: 2152-61. 


\section{Supplementary Files}

This is a list of supplementary files associated with this preprint. Click to download.

- Graphicalabstractimage.png

- SupplementaryMaterial.docx 